\title{
Molecular and morphological characterization of EMS-induced chili pepper mutants resistant to Chili veinal mottle virus
}

\author{
IFA MANZILA ${ }^{1, \bullet}$, TRI PUJI PRIYATNO ${ }^{1}$, KRISTIANTO NUGROHO ${ }^{1}$, \\ RERENSTRADIKA TIZAR TERRYANA ${ }^{1}$, PUJI LESTARI ${ }^{1}$, SRI HENDRASTUTI HIDAYAT ${ }^{2}$ \\ ${ }^{1}$ Indonesian Center for Agricultural Biotechnology and Genetic Resources Research and Development. Jl. Tentara Pelajar 3A Bogor 16111, West Java, \\ Indonesia. Tel.: +62-251-8337975, Fax.: +62-251-8338820, "email: ifamanzila@gmail.com \\ ${ }^{2}$ Department of Plant Protection, Institut Pertanian Bogor. Jl. Kamper, Dramaga Campus, Bogor 16680, West Java, Indonesia
}

Manuscript received: 23 October 2019. Revision accepted: 15 March 2020.

\begin{abstract}
Manzila I, Priyatno TP, Nugroho K, Terryana RT, Lestari P, Hidayat SH. 2020. Molecular and morphological characterization of EMS-induced chili pepper mutants resistant to Chili veinal mottle virus. Biodiversitas 21: 1448-1457. Chili veinal mottle virus (ChiVMV) is a major prevalent virus that potentially reduces the yield of chili pepper by more than $50 \%$ in Indonesia. Therefore, the development of a ChiVMV-resistant cultivar is necessary to ensure satisfactory chili pepper production. Mutation breeding is a promising tool available to produce virus-resistant plants via the induction of new alleles due to point mutations within the existing chili germplasm. This research was conducted to assess the genetic variation of ten promising (M6) EMS-induced mutant lines of chili pepper (Capsicum annuum L.) potentially resistant to ChiVMV by their morphological characteristics and SSR profile, as well as identify potential mutants based on agronomic traits. The ten chili pepper mutant lines used in the present study were derived from the shoot tips of a Gelora cultivar treated with $0.5 \%$ ethyl methanesulfonate (EMS) as a chemical mutagen. The performance of the respective promising chili pepper mutant lines both at a molecular and morphological level was observed. Phenotypic analysis showed that all the promising chili pepper mutant lines underwent significant morphological changes. Of these, the phenotype coefficient variation $(\mathrm{PCV})$ values were higher than the genotype coefficient variation $(\mathrm{GCV})$ values for all the traits observed. High heritability $\left(h_{2}\right)$ was found for the canopy area, length of the fruit stalk, fruit weight, fruit weight per plant, thick fruit flesh, leaf width, leaf length, and fruit storage duration. A total of 52 alleles were detected from the five polymorphic SSR loci with 5.2 average alleles/loci. A dendrogram was generated and revealed two groups with five mutants clustered separately from their parents which could be valuable for further improvement.
\end{abstract}

Keywords: Capsicum annuum, Chili veinal mottle virus, mutant lines, SSR

Abbreviations: ChiVMV: Chili veinal mottle virus, EMS: Ethyl Methanesulfonate, SSRs: Single Sequence Repeats, PCV: Phenotype Coefficient Variation, GCV: Genotype Coefficient Variation

\section{INTRODUCTION}

Viral diseases are one of the most serious diseases of chili in many areas where the crop is grown. The incidence of chili-infected viruses has increased considerably over the past 30 years due to the increased volume and speed of global trade of fresh produce carrying viruses and vectors to new locations (Kenyon et al. 2014). In Indonesia, Chili veinal mottle virus (ChiVMV) causes serious losses in chili and has become the most limiting factor affecting chili production besides Pepper yellow leaf curl virus (PepYLCV), Cucumber mosaic cucumovirus (CMV), Ralstonia solanacearum, Phytophthora capsici, and Colletotrichum spp. (Hidayat et al. 2012; Bhattarai and Mariyono 2016). This virus may cause yield loss of up to $95 \%$ and $30 \%$ in sweet chili and small chili, respectively (Greene et al. 2003). Chili infected by ChiVMV show typical symptoms, which consist of irregular dark green spots on the leaf (i.e., mottling), a vein banding leaf malformation (Tsai et al. 2011), and reduction in fruit size (Shah et al. 2001). Efforts to control ChiVMV using pesticides to control insect vectors, removal of diseased plants, and agronomic intervention are not yet satisfactory. The use of host plant resistance to this disease is considered to be an effective, economical, ecologically safe, and durable approach. However, to the best of our knowledge, there are no resistance varieties of chili peppers in Indonesia to date. Therefore, the development of ChiVMVresistant chili pepper varieties is necessary.

Breeding for resistance to ChiVMV requires resistant germplasm for crop improvement. As a non-center origin of chili peppers, Indonesia has chili peppers with narrow genetic variability. Therefore, mutation via the breeding approach could promisingly be used as an effective tool to broaden the genetic variability in the existing varieties. Based on the mutation breeding program, the improvement in genetic variability could be conducted by several strategies, such as T-DNA or transposon insertional mutagenesis (Alonso et al. 2003) and physical- and chemically-induced mutagenesis ( Uchida et al. 2011; Ramezani et al. 2017). Ethyl methanesulfonate (EMS) is an effective chemical mutagen to induce random point mutations resulting in mispairing among these nucleotides with their complementary bases and, thus, the introduction 
of base changes after replication (Ramezani et al. 2017). As an alkylating agent, EMS results in the build-up of O6ethylguanine on guanine $(G)$ residues, which will mispair with thymine (T) instead of cytosine (C) (Aswaneeza et al. 2015). Mispairing of adenine (A)/T will occur through continuous DNA repair in replacement to $\mathrm{G} / \mathrm{C}$ pairing (Greene et al. 2003). A previous study reported that EMS treatment caused $70 \%-99 \%$ of $\mathrm{C} / \mathrm{G}$ to $\mathrm{A} / \mathrm{T}$ changes in base pairing among mutant organisms (Till et al. 2007).

We conducted a previous study (Manzila et al. 2015) to improve the genetic variability of the local big chili pepper variety (Gelora cultivar) through EMS mutagenesis in combination with somaclonal variation. From these genetic resources, we successfully identified, characterized, and developed ChiVMV-resistance mutant lines. Ten promising chili mutant lines in the sixth generation (M6), which is resistant to ChiVMV, were assessed at a morphological and molecular level. DNA markers, such as amplified fragment length polymorphisms (AFLPs), random amplified polymorphic DNA (RAPD), anchored simple sequence repeat polymorphisms (ISSRs), and simple sequence repeats (SSRs), have been used to detect variation at a DNA level and to determine interrelationships among closely related genotypes (Schulman 2007; Geleta et al. 2005; Aslam and Arif 2014; Dhaliwal et al. 2014; Bahurupe et al. 2018; Sharmin et al. 2018. SSRs are an excellent molecular marker system for many types of genetic analyses, including linkage mapping germplasm surveys and phylogenetic studies (Alvarez et al. 2007). They have been used to characterize genetic diversity in several crop species, including sorghum maize, cotton, wheat, and rice (Herrera et al. 2008). All results showed that SSR markers efficiently detected genetic polymorphisms and discriminated among genotypes (Alvarez et al. 2007; Giarrocco et al. 2007). The objectives of this study were to determine the effect of EMS on the genetic variability of ten promising chili pepper mutant lines potentially resistant to ChiVMV and to evaluate their genetic differentiation using SSR markers.

\section{MATERIALS AND METHODS}

\section{Genetic materials}

A set of 10 EMS-induced Gelora mutant lines of the sixth generation (M6) and Gelora cultivar (wild type) were used as experimental materials (Manzila et al. 2015). The 10 potential mutant lines used in this study were derived from a previous selection of 800 mutant lines based on resistance to ChiVMV, good morphological characteristics, and high yield. The 10 mutant lines utilized were M6.121.1, M6.238.1, M6.2338.2, M6.353.1, M6.420.1, M6.517.1, M6.517.2, M6.801.1, M6.113.3, and M6.200.2. The study was conducted at the Vegetables Research Institute (IVEGRI) in Lembang-Bandung, West Java, Indonesia with a latitude and longitude 648'7.8192" S during the dry season of 2016.

\section{Morphological characterization}

To observe morphological characterization, the chili pepper mutant lines were sown in a $2 \times 2 \mathrm{~m}^{2}$ seedbed. The experiment was arranged in a randomized completely block design (RCBD) with four replications. The beds were prepared by adding a sufficient amount of organic manure (12 ton/ha). The seedlings were protected from virus vectors via a nylon net covering. Thirty-day-old seedlings were then transplanted in replicated plots. The size of each plot used in this study was $6 \times 1 \mathrm{~m}$ on $40 \mathrm{~cm}$-high raised beds. An adequate quantity of organic manure and inorganic fertilizer (NPK: 90:60:40 kg/ha) was applied before covering the beds with silver mulch. Twenty-four plants were accommodated in each plot by following a spacing of $60 \times 50 \mathrm{~cm}$. Usual agronomic and plant protection practices were adopted to grow the plants in the experimental field. Mutant lines were characterized by 15 morphological characteristics. An analysis of variance was conducted with SAS 9.0 to determine the genetic variation in the measured traits. Phenotypic coefficients of variation (PCV), genotypic coefficients of variation (GCV), coefficients of variation, and heritability were calculated according to the method by Narayana and Singh (2015). Phenotypic and genotypic correlation was calculated by the formula suggested by Falconer (1989).

\section{Plant resistance analysis}

Propagation of the virus inoculum

The ChiVMV used in this study was isolated from Cikabayan, Bogor, West Java, and collected by the Plant Protection Department of Bogor Agricultural University in Indonesia. These isolates were propagated in sweet chili plants (Capsicum annum) via mechanical transmission. Thirty-day-old sweet chili plants were mechanically inoculated with pure ChiVMV isolates by grinding ChiVMV infected leaves (w/v) in $0.01 \mathrm{M}$ phosphate buffer (pH 7.0) with a sterile mortar (Figure 1). Subsequently, the leaves' juice extract was mixed with 400-grit carborundum and rubbed on the surface of the leaves. After 10-20 min of inoculation, the leaves were washed with distilled water (Hull 2009).

\section{Evaluation of ChiVMV-resistant chili}

The seeds of chili plants were sown on sterilized soil media mixed with manure in a ratio of $1: 3$. The soil mixture was incubated first for three days before use. After the first leaf appeared, the chili seedlings were transferred to a polybag, maintained for 30 days, and inoculated with ChiVMV. Mechanical inoculation of ChiVMV was conducted by applying the inoculum to the leaves of 10 mutant lines. As a positive control, the leaves of healthy plants were smeared with phosphate buffer solution. All inoculation treatments were performed twice with a oneweek interval. Inoculated chili plants were maintained in a greenhouse until they showed ChiVMV infection symptoms. The parameters observed were the incubation period, disease incidence, disease severity, plant height, number of fruits per plant, and fruit weight of each plant. The disease incidence was observed three times starting one week after inoculation until the next 30 days with a 
one-week interval for each observation. The mean value was calculated from the three observations.

\section{SSR analysis}

\section{DNA isolation}

Genomic DNA was extracted from young leaves of chili plants according to the CTAB-based protocol. Approximately $100 \mathrm{mg}$ of each leaf sample was ground in a mortar and pestle in the presence of liquid nitrogen to obtain a fine powder. The powder was transferred to a 2-ml centrifuge tube containing $500 \mu \mathrm{l}$ of pre-warmed extraction buffer $(100 \mathrm{mM}$ Tris-HCl pH 8.0, $1.4 \mathrm{M} \mathrm{NaCl}, 20 \mathrm{mM}$ EDTA, $2 \% \mathrm{w} / \mathrm{v}$ CTAB, and $0.1 \% \beta$-mercaptoethanol) and mixed by inversion. Then, the tubes were kept in a thermostatic water bath at $65^{\circ} \mathrm{C}$ for $60 \mathrm{~min}$. DNA was extracted with chloroform: isoamyl alcohol mixes (24:1), precipitated using two volumes of absolute ethanol in the presence of $0.3 \mathrm{M}$ sodium acetate, and pelleted by centrifugation. The pellets were then washed with $70 \%$ ethanol, air dried, and dissolved in distilled water. The DNA pellet was air-dried and re-dissolved in $50 \mu \mathrm{l}$ of TE buffer (10 mM Tris-HCl, 1 mM EDTA, pH 8.0).

\section{PCR amplification}

PCR experiments were performed in a volume of $20 \mu \mathrm{l}$ containing $30 \mathrm{ng}$ of template DNA, 4 pmol of each primer, $3 \mathrm{mM}$ of each dNTP, 1 unit of Taq DNA polymerase, 2.5 $\mathrm{mM} \mathrm{MgCl}_{2}$ and $1 \mathrm{x}$ PCR buffer. Ten SSR primer pairs that were selected from the publicly available collection of the chili database genome (www.genom.litbang.pertanian.go.id) were used for molecular analysis. The amplification reactions were performed using the following thermal profile: $95^{\circ} \mathrm{C}$ for 5 min, 35 cycles of $30 \mathrm{~s}$ at $94^{\circ} \mathrm{C}, 60 \mathrm{~s}$ at the specific-primer annealing temperature, and $60 \mathrm{~s}$ at $72^{\circ} \mathrm{C}$. The last cycle was followed by $10 \mathrm{~min}$ at $72^{\circ} \mathrm{C}$, and PCR was terminated with a continuous cycle at $4^{\circ} \mathrm{C}$. The amplification reactions were performed using a DNA thermal cycler (Bio-Rad, Model 580BR). The amplification products were separated by electrophoresis on $12 \%$ non-denaturing polyacrylamide gels (Atto, Tokyo, Japan) and visualized by silver staining with a 100 bp DNA ladder (Fermentas, Germany) as a reference.
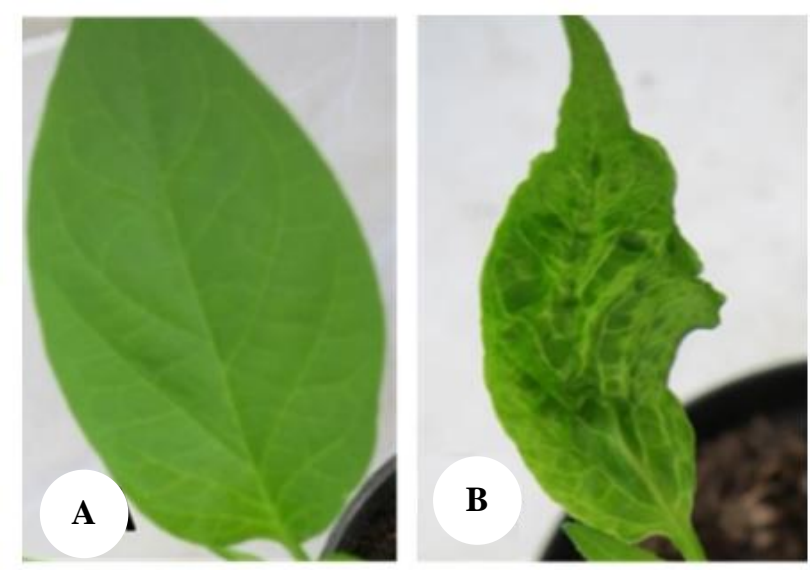

Figure 1. Chili pepper leaves showing characteristic uninfected (A) and infected by ChiVMV

\section{SSR data analysis}

The summary statistics, including the number of alleles per locus, major allele frequency, gene diversity, and polymorphism information content (PIC) values were determined using POWER MARKER version 3.25 (Liu and Muse 2005), a genetic marker data analysis software. The individual fragments were assigned as alleles of the appropriate microsatellite loci. The allele frequency data from POWER MARKER was used to export the data in binary format (the presence of the allele as 1 and the absence of the allele as 0 ) for analysis with the Numerical Taxonomy and Multivariate Analysis System (NTSYS-PC) Version 2.2 software (Rohlf 2017). An unweighted pair group method of arithmetic means (UPGMA) dendrogram was constructed using a computer program (i.e., POPGENE version 1.31) based on Nei 1973) genetic distance. The diversity levels of loci were evaluated by the PIC value according to a formula (Smith et al. 1997) where $\mathrm{Pi}$ is the frequency of the pattern for marker $\mathrm{i}$ and the summation extends over $n$ patterns.

$$
P I C=1-\sum_{i}^{n}(P i)^{2}
$$

\section{RESULTS AND DISCUSSION}

\section{Morphological diversity of chili mutants}

The analyses of variance (ANOVA) results for the studied traits are presented in Table 1 . All the mutant lines showed highly significant differences $(\mathrm{P}<0.01)$ in their morphological and yield-related traits, except for the length of fruit (LF) traits. These data suggest that the morphological traits of the EMS-induced chili mutant exhibited significant changes compared to the wild type. The changing of morphological traits is the common phenomenon observed in mutant plants induced by EMS possibly due to severe damage of mutagens to plant genetic materials, and this effect, in turn, reflected on the change in growth and development factors (Arisha et al. 2015). Gandhi et al. (2014) also reported that EMS-chili induced mutants showed various quantitative traits, such as germination percentage, plant height, primary and secondary branches per plant, days to first flowering, fruit length, fruit girth, total number of fruits per plant, number of seeds per fruit, seed weight per fruit, 100-seed weight, and pericarp. This finding indicates that EMS-induced mutation of Gelora resulted in genetic variability among mutant lines.

In the present study, the PCV value (Table 1) was slightly higher than the GCV value for all traits. Among all traits, the diameter of the fruit exhibited high estimates of GCV and PCV (16.23\% and $21.52 \%$, respectively) followed by the number of fruit per plant (NFP) $(19.02 \%$ and $20.72 \%$, respectively). According to Robinson et al. (1949), PCV and GCV values greater than $20 \%$ are considered high; values between $10 \%$ and $20 \%$ are considered moderate; and values less than $10 \%$ are considered low. The high GCV and PCV values indicated 
the possibility of effective selection based on these traits. Traits with low GCV and GCV values showed a limited scope for improvement.

The heritability value indicates the transmission index of traits from parents to their progeny that is important for the plant breeders to select the desired genotypes from a diverse genetic background. Estimation of heritability in a broad sense ranged from $32.3 \%$ for the length of the fruit to $98.7 \%$ for the fruit storage duration (Table 2). Narayana and Singh (2015) mentioned that heritability values greater than $80 \%$ were very high; values of $60 \%-79 \%$ were moderately high, values of $40 \%-59 \%$ were medium; and values less than $40 \%$ were low. Based on that classification, traits with high heritability values were the canopy area, length of the fruit stalk, fruit weight, fruit weight per plant, thick fruit flesh, leaf width, leaf length, and fruit storage duration. The traits with very high heritability values were less influenced by environmental factors, so phenotypic selection can be fairly easy. High estimates of heritability have also been reported by previous researchers for the number of fruit per plant, fruit weight, fruit weight per plant (Qosim et al. 2013), canopy diameter (Yadeta et al. 2011), and fruit girth (Sreelathakumary and Rajamony 2004).

The genotypic correlation coefficient showed a measure of the genetic association between characteristics and may determine the component character on which selection can be based to improve chili yield (Can and Yoshida, 1999). Positive significant associations were obtained between the number of fruit per plant as the major component of fruit production and the growth parameters (leaf width, leaf length, and length of the leaf stalk) (Table 2). A similar result showing the correlation between the number of fruit per plant and the growth parameters was also reported by Bijalwan and Mishra 2017, Jodi et al. 2017, Ajjapplavara et al. 2005, and Chattopadhyay et al. 2011. Therefore, the present study indicated that leaf width, leaf length, and length of the leaf stalk were the main components contributing to the number of fruit per plant, and it is logical to give a high priority to selecting genotypes that perform well for growth contribution which would simultaneously help improve the yield. This finding indicated that an improvement in chili resistance to ChiVMV causing narrowing and distortion of the leaves followed by stunted growth was crucial in increasing fruit production. These findings were in accordance with those of Ajjapplavara et al. (2005), who reported that the fruit yield per plant significantly correlated with the leaf curl complex incidence in chili.

\section{Incidence and intensity of viral symptoms}

Observations 30-56 days after planting revealed the absence of mosaic symptoms caused by ChiVMV either alone or in combination with other viruses, such as potato virus $Y$ (PVY), CMV, tobacco mosaic virus (TMV) or tomato mosaic virus (ToMV), and tobacco etch virus (TEV). In contrast, the intensity of mosaic symptoms and disease incidence on chili control (surge) were $28 \%$ and $59 \%$, respectively. Some of the chili plant mutant lines were infected with ChiVMV 37 days after planting but were not evenly distributed. The incidence and intensity of the symptoms were first observed in M6.122.1, and infected chili plant mutants increased with the age of the plant. Three chili mutant lines (i.e., M6.113.3, M6.517.2, and M6.420.1) showed lower severity (15\%-29\%) and disease incidence (26\%-39\%) than the seven other chili mutant lines. In addition, the disease intensity and incidence of seven other mutant lines (i.e., M6.121.1, M6.238.1, M6.2338.2, M6.353.1, M6.517.1, M6.801.1, and M6.200.2) ranged from $39 \%-61 \%$ and $52 \%-79 \%$, respectively (Figure 2). Thus, the M6.113.3, M6.517.2, and M6.420.1 mutant lines can potentially be further developed into new varieties that are resistant to ChiVMV.

Table 1. Variance component and heritability of quantitative characteristics in chili peppers

\begin{tabular}{|c|c|c|c|c|c|c|c|c|c|c|}
\hline Characteristics & Mean \pm SD & Min & Max & $\mathrm{CV}$ & GV & PV & GCV & PCV & h2 & $\begin{array}{l}\text { Mutant lines } \\
\text { (ANOVA) }\end{array}$ \\
\hline $\mathrm{PH}(\mathrm{cm})$ & $63.28 \pm 3.70$ & 56.67 & 67.24 & 4.0 & 10.73 & 17.16 & 5.22 & 6.60 & 62.5 & $49.346^{* *}$ \\
\hline $\mathrm{CA}\left(\mathrm{cm}^{2}\right)$ & $65.27 \pm 3.66$ & 59.42 & 69.99 & 1.1 & 13.59 & 14.15 & 5.66 & 5.77 & 96.1 & $54.932 * *$ \\
\hline $\mathrm{LF}(\mathrm{cm})$ & $12.20 \pm 0.62$ & 11.11 & 12.87 & 5.1 & 0.18 & 0.57 & 3.56 & 6.26 & 32.3 & 1.127 \\
\hline LFS (cm) & $4.46 \pm 0.45$ & 3.95 & 5.13 & 2.8 & 0.18 & 0.20 & 9.57 & 9.98 & 92.0 & $0.737 * *$ \\
\hline $\mathrm{DF}(\mathrm{cm})$ & $1.49 \pm 0.28$ & 1.29 & 2.00 & 14.1 & 0.06 & 0.11 & 16.23 & 21.52 & 56.9 & $0.284 * *$ \\
\hline FW $(\mathrm{g})$ & $13.40 \pm 1.48$ & 11.64 & 15.46 & 2.5 & 2.16 & 2.28 & 10.97 & 11.25 & 95.0 & $8.764 * *$ \\
\hline NFP & $156.28 \pm 29.53$ & 123.67 & 195.33 & 8.2 & 885.48 & 1050.68 & 19.02 & 20.72 & 84.3 & $3707.117 * *$ \\
\hline FWP (kg) & $2.11 \pm 0.27$ & 1.75 & 2.42 & 2.0 & 0.08 & 0.08 & 13.08 & 13.22 & 97.8 & $0.304 * *$ \\
\hline TFF (mm) & $2.95 \pm 0.42$ & 2.38 & 3.53 & 4.1 & 0.18 & 0.19 & 14.25 & 14.82 & 92.4 & $0.721 * *$ \\
\hline $\mathrm{LW}(\mathrm{cm})$ & $3.64 \pm 0.40$ & 3.11 & 4.21 & 1.4 & 0.17 & 0.17 & 11.26 & 11.35 & 98.5 & $0.678 * *$ \\
\hline $\mathrm{LL}(\mathrm{cm})$ & $8.81 \pm 0.44$ & 8.30 & 9.39 & 0.6 & 0.19 & 0.20 & 4.99 & 5.04 & 98.4 & $0.778 * *$ \\
\hline $\operatorname{LLS}(\mathrm{cm})$ & $8.62 \pm 106$ & 7.47 & 10.11 & 1.2 & 0.66 & 0.97 & 1.75 & 2.13 & 68.0 & $2.947 * *$ \\
\hline FA (days after transplant) & $46.34 \pm 0.79$ & 45.33 & 47.28 & 0.4 & 0.80 & 0.93 & 0.94 & 1.01 & 85.4 & $3.323 * *$ \\
\hline EHA (days after transplant) & $95.42 \pm 0.88$ & 94.67 & 97.11 & 2.0 & 0.86 & 0.94 & 6.73 & 7.01 & 92.0 & $3.527 * *$ \\
\hline FSD (days after harvest) & $13.82 \pm 0.96$ & 12.00 & 14.78 & 0.2 & 0.01 & 0.02 & 1.61 & 1.62 & 98.7 & $0.059 * *$ \\
\hline
\end{tabular}

Notes: plant height (PH); canopy area (CA); length of the fruit (LF); length of the fruit stalk (LFS); diameter of the fruit (DF); fruit weight (FW); number of fruit per plant (NFP); fruit weight per plant (FWP); thick fruit flesh (TFF); leaf width (LW); leaf length (LL); length of the leaf stalk (LLS); flowering age (FA); early harvest age (EHA); fruit storage duration (FSD). 
Table 2. Correlation matrix of important morpho-agronomical traits observed in this study

\begin{tabular}{|c|c|c|c|c|c|c|c|c|c|c|c|c|c|c|c|}
\hline Characteristics & PH & CA & $\mathbf{L F}$ & LFS & DF & FW & NFP & FWP & TFF & $\mathbf{L W}$ & $\mathbf{L} \mathbf{L}$ & LLS & FA & EHA & FSD \\
\hline $\mathrm{PH}$ & 1.000 & & & & & & & & & & & & & & \\
\hline $\mathrm{CA}$ & $0.696 * *$ & 1.000 & & & & & & & & & & & & & \\
\hline LF & $-0.811 * *$ & -0.445 & 1.000 & & & & & & & & & & & & \\
\hline LFS & 0.235 & -0.035 & $-0.517 * *$ & 1.000 & & & & & & & & & & & \\
\hline DF & 0.274 & -0.138 & $-0.677 * *$ & $\mathbf{0 . 7 1 8} * *$ & 1.000 & & & & & & & & & & \\
\hline FW & $0.794 * *$ & $0.719 * *$ & $-0.801 * *$ & $0.612 * *$ & 0.361 & 1.000 & & & & & & & & & \\
\hline NFP & 0.071 & 0.097 & $-0.526 * *$ & 0.120 & $0.619 * *$ & 0.154 & 1.000 & & & & & & & & \\
\hline FWP & $-0.549 * *$ & -0.149 & 0.073 & 0.107 & 0.239 & -0.140 & $0.692 * *$ & 1.000 & & & & & & & \\
\hline TFF & 0.013 & 0.227 & -0.417 & 0.442 & $0.663^{* *} *$ & 0.337 & $0.814^{* *}$ & $0.743 * *$ & 1.000 & & & & & & \\
\hline LW & 0.085 & 0.182 & -0.438 & 0.409 & $0.750 * *$ & 0.272 & $0.801 * *$ & $0.601 * *$ & $0.962 * *$ & 1.000 & & & & & \\
\hline LL & 0.228 & 0.187 & $-0.650 * *$ & 0.098 & 0.439 & 0.322 & $0.877 * *$ & $0.550 * *$ & $0.567 * *$ & $0.481^{*}$ & 1.000 & & & & \\
\hline LLS & -0.439 & $-0.579 * *$ & -0.149 & 0.360 & $0.487 *$ & -0.145 & $0.573^{* *} *$ & $0.703 * *$ & 0.421 & 0.320 & $0.598 * *$ & 1.000 & & & \\
\hline FA & 0.023 & 0.001 & 0.046 & 0.151 & 0.082 & 0.122 & $0.470 *$ & 0.049 & 0.128 & 0.127 & 0.115 & $0.610 * *$ & 1.000 & & \\
\hline EHA & -0.016 & -0.062 & -0.027 & -0.022 & 0.049 & -0.097 & 0.426 & 0.025 & 0.037 & 0.058 & 0.099 & 0.024 & 0.353 & 1.000 & \\
\hline FSD & 0.029 & -0.017 & -0.016 & -0.117 & -0.008 & -0.082 & 0.077 & -0.037 & -0.067 & -0.047 & 0.043 & -0.004 & -0.008 & $0.611 * *$ & 1.000 \\
\hline
\end{tabular}




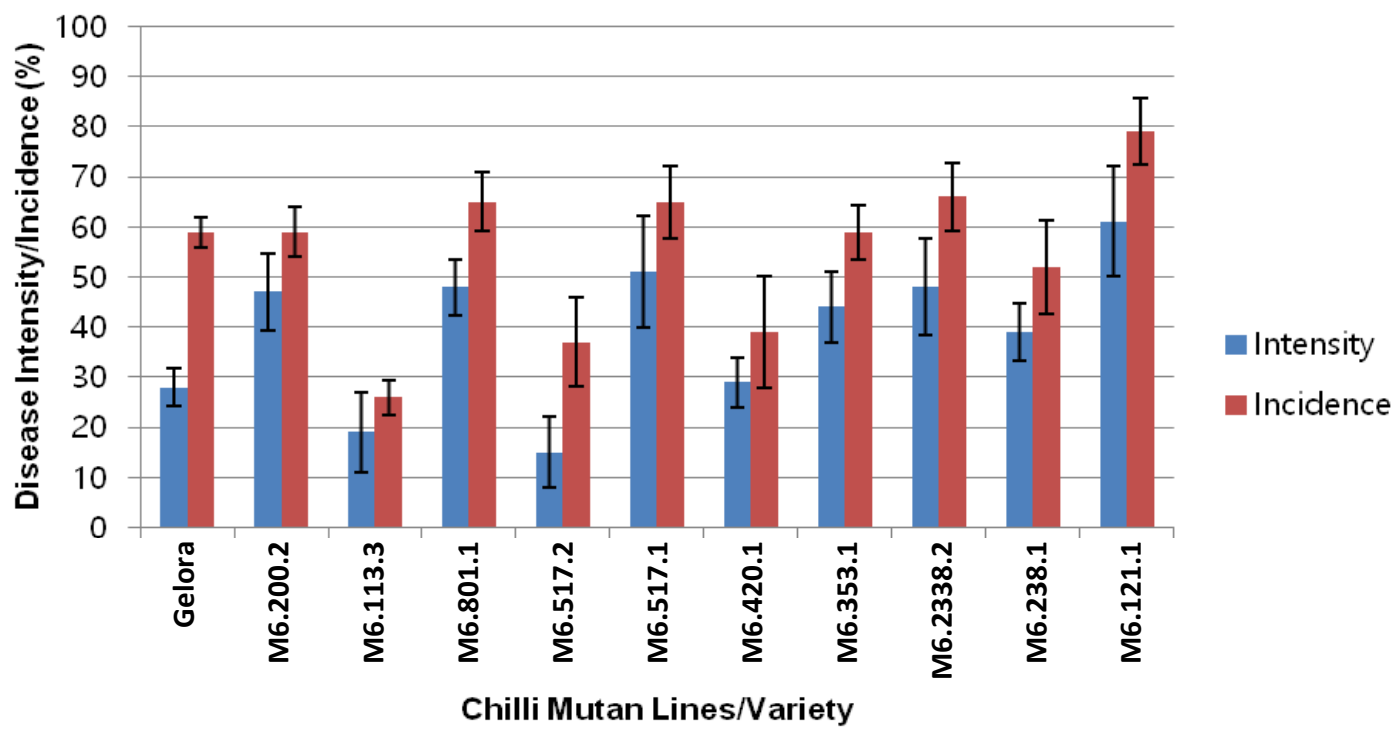

Figure 2. The incidence and intensity of symptoms of Chili veinal mottle virus

Some cases of plant resistance to family Potyviridae are caused by a recessive gene mutation that encodes a host factor critical for viral infection (Hashimoto et al. 2016). The most widely identified recessive resistance genes as a host factor are Eukaryotic translation initiation factor (eIF) $4 E$ and $e I F 4 G$ and their isoforms. (Yoshii et al. 2004) reported an EMS-induced mutation in Arabidopsis thaliana eIF4E1 (cum1-1), resulting in a stop codon at position 99, was shown to reduce CMV multiplication and increase plant resistance. Resistance mediated by eIF4Es mutation to other viruses is also determined in several resistant crop cultivars, such as in Arabidopsis to turnip crinkle virus (TCV) (Yoshii et al, 1998), melon (Cucumis melo) to melon necrotic spot virus (MNSV) (Nieto et al. 2006), barley to barley mild mosaic virus (BaMMV) and barley yellow mosaic virus (BYMV) (Kanyuka et al. 2005), and rice to rice yellow mottle virus (RYMV) (Albar et al. 2006).

\section{Molecular diversity based on the SSR marker}

The SSR primer pairs used for the analysis of genetic diversity, number of alleles for each SSR locus, and PIC values are shown in Table 3 . The results showed that all primers are reproducible and had distinct polymorphic amplification (Figure 2). A total of 52 alleles were detected for five polymorphic SSR loci with an average of 5.2 alleles/loci and a range between 3 and 8 alleles. One SSR primer (i.e., C2 At1914810) produced the maximum number of alleles (8) with an allelic frequency of 0.41 , followed by CaSSR 3.2, CaSSR 1.2, AGi 55, CaSSR 197, CaSSR 3.1, and CaSSR 246. Gene diversity ranged from 0.60 to 0.81 with the highest value of gene diversity shown by CaSSR 1.2 followed by AGi 55, CaSSR 3.2, CaSSR 246, C2 At1914810, and CaSSR 3.1. The total genetic diversity obtained was 7.16 with an average of 0.72 . The PIC value for ten markers ranged from 0.53 to 0.78 with a mean value of 0.67 . The highest PIC value (0.78) was obtained for CaSSR 1.2, followed by AGi 55, CaSSR 3.2, C2 At1914810, CaSSR 246, and CaSSR 3.1. Therefore, these primers were considered the best markers to differentiate the 10 chili pepper mutants.

SSRs are one of the most attractive markers for plant genetics and breeding due to their locus-specific and multiallelic exhibition of co-dominant transmission, their ease of detection by PCR, and their high rates of transferability across species (Zalapa et al. 2012). SSRs have been extensively involved in a variety of applications, including cultivar identification, the determination of hybridity, genetic diversity assessment, genetic mapping, gene tagging, gene flow, and molecular evolution in various plant and animal systems (Cheng et al. 2016). In this study, we used SSR markers to discriminate close genotypes of EMS-induced chili mutant lines.

EMS mutagenesis caused poIntl mutations in nucleotide sequences in some parts of the genome, and then, it caused dissimilarity in morphological characteristics among the chili pepper mutant lines. Genetic variation in mutant populations is a worthy source for enlarging the range of genetic materials in plant breeding, and molecular markers, such as SSRs, are effective tools for discovering genetic diversity (Nachimuthu et al. 2015). Molecular markers have been successfully used in the genus Capsicum to select parents for hybrid production for intra-specific or inter-specific classification and for the analysis of variation (Kwon et al. 2002). Similarly, we found that SSR markers could detect a very high level of polymorphism (100\%) in EMS-induced chili mutant lines in the present study. 
Table 3. Summary statistics of SSR polymorphisms in this study

\begin{tabular}{lccccc}
\hline \multicolumn{1}{c}{ Primer code } & Number of alleles & Allele frequency & Gene diversity & PIC value & Heterozygosity \\
\hline CaES 5502 & 3 & 0.55 & 0.60 & 0.53 & 0 \\
CaSSR 246 & 5 & 0.27 & 0.78 & 0.74 & 0 \\
CaSSR 197 & 5 & 0.59 & 0.60 & 0.56 & 0.09 \\
AGi 55 & 6 & 0.27 & 0.79 & 0.76 & 0 \\
CAEM S396 & 4 & 0.45 & 0.64 & 0.58 & 0 \\
C2 At1914810 & 8 & 0.41 & 0.77 & 0.74 & 0.18 \\
CaSSR 1.2 & 6 & 0.27 & 0.81 & 0.78 & 0 \\
CaSSR 2.2 & 4 & 0.55 & 0.63 & 0.58 & 0 \\
CaSSR 3.1 & 5 & 0.36 & 0.76 & 0.72 & 0 \\
CaSSR 3.2 & 6 & - & 7.16 & 0.75 & - \\
Total & 52 & 0.41 & 0.72 & 0.67 & 0 \\
Average & 5.2 & & & 0.03 \\
\hline
\end{tabular}
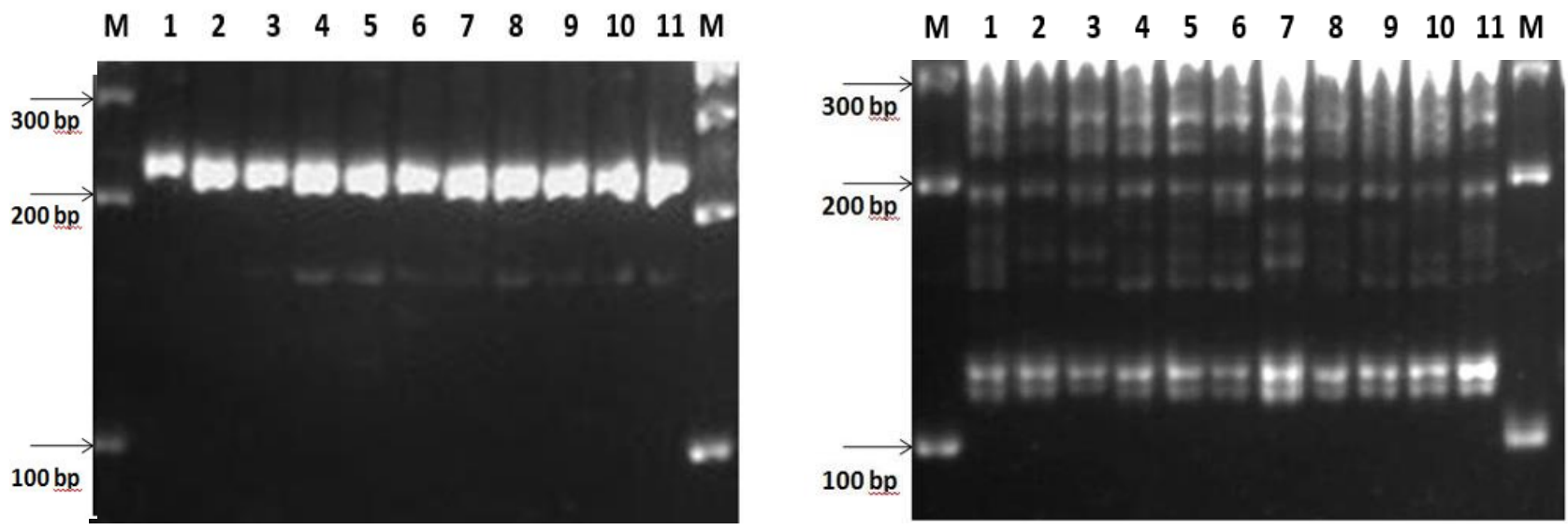

Figure 2. SSR profiles of the ten chili mutant lines using the a. AGi 55 and b. C2 At1914810 primers; lanes 1-10: mutant lines; lane 11: parent (Gelora); M: 100 bp DNA ladders

The ten SSR primers used to screen a set of ten chili mutant lines that differed in morphological traits revealed high polymorphism producing many alleles per locus. In the current study, the average number of SSR alleles was 5.2 for 27 polymorphic loci. This number is higher than the number of SSR alleles obtained by Kwon et al. (2002), which was on average 3.3 alleles per locus in pepper $(C$. anпиит) varieties. The use of SSR primers in previous reports resulted in the detection of 375 alleles of gammairradiated cowpea mutants (Olasupo et al. 2018), 314 alleles of MNU-induced rice mutants (Anh et al. 2018), and 1.8 alleles of EMS and in vitro-induced tomato mutants (Shalaby and El-Banna, 2013). In addition, the PIC values of 10 SSR markers in the present study ranged from 0.53 to 0.78 with an average of 0.67 . These results were similar to the PIC values for pepper varieties (0.53) (Kwon et al. 2002), gamma-irradiated cowpea mutants (0.51) (Olasupo et al. 2018), and MNU-induced rice mutants (0.51) (Anh et al. 2018). SSR markers with a PIC value of 0.5 or higher were considered effective in discriminating the polymorphism rate (Anupam et al. 2017), and they have potential in the evaluation of genetic divergence (Anh et al. 2018). Therefore, a high level of polymorphism of markers could indicate that the chili pepper mutants used in this study were more diverse. These EMS-chili pepper mutants can be employed to enlarge the genetic foundation of the current genotypes.

In addition, the PIC value is a principal factor in distinguishing the percentage of polymorphism of a marker at a specific locus and revealing the maximum genetic information among mutants (Salem and Sallam, 2016). The PIC values of four polymorphism markers (i.e., CaES 5502, CaSSR 197, CAEM S396, and CaSSR 2.2) indicate moderate genetic diversity among chili mutants, and six markers (i.e., CaSSR 246, AGi 55, C2 At1914810, CaSSR 1.2, CaSSR 3.1, and CaSSR 3.2) showed high PIC values $(0.72 \leq$ PIC $\leq 0.78)$. Anupam et al. (2017) stated that SSR markers with a PIC value $>0.5$ are considered effective in the evaluation of genetic variability. Thus, the 10 primers used in the study were highly informative in revealing the genetic diversity and partitioning of genetic variation due to their higher number of alleles per locus as well as higher PIC values.

Genetic distance among the 10 chili mutant lines ranged from 0.212 to 0.423 (Table 4). The highest genetic distance was observed between the M6.2338.2 mutant and the M6.200.2 mutant (0.423); the M6.2338.2 mutant and the M6.801.1 mutant (0.385); the M6.2338.2 mutant and the 
parent (0.385); and the M6.517.1 mutant and the M6.801.1 mutant (0.385); whereas the lowest genetic identity was observed between the M6.420.1 mutant and the M6.113.3 and M6.200.2 mutants (0.212). The difference between the highest and lowest genetic identity indicates the presence of variability among the 10 chili mutant lines and the wild type. A mutant line pair with a higher genetic distance is more dissimilar than a pair with a lower genetic distance. A lower genetic distance indicates that they are genetically much closer. The genetic distance between the wild type (Gelora cultivar) and mutant line ranged from 0.615 to 0.731. This result indicated that the wild type and chili pepper mutant lines used in the present study were genetically different.

All 11 chili mutant lines were grouped into two main clusters, which were further divided into two sub-clusters (Figure 2 and Figure 3). The first sub-cluster contained five mutant lines: M6.121.1; M6.238.1; M6.517.1; M6.2338.2 and M6.353.1. The second sub-cluster consisted of five mutant lines (i.e., M6.420.1; M6.113.3I; M6.801.1; M6.517.2; and M6.200.2) and the wild type (Parent (K). The dendrogram grouped vast of the mutants into two clusters, indicating a higher level of molecular diversity among the mutant lines. High polymorphism has also been previously reported in EMS-induced mutants (Khalil et al. 2018 Sadat and Hoveize 2012 Aswaneeza et al. 2015). The UPGMA clustering analysis delineated all 11 genotypes into two clusters with different genotypes indicating the greatness of the genetic variation among the chili mutant genotypes. Cluster I represented five mutant genotypes, while cluster II consisted of six genotypes that originated from the wild type and mutant lines, indicating their higher genetic similarity. The SSR analysis demonstrated the distinctness between mutant lines and their parent relevant to the phenotypic traits. These results could be due to the fact that EMS-induced mutations in chili peppers may change the genetic material, and these changes lead to genetic differentiation among chili mutant lines.

Table 4. Nei's genetic distance (below diagonal) values among 11 chili mutant lines

\begin{tabular}{|c|c|c|c|c|c|c|c|c|c|c|c|}
\hline $\begin{array}{c}\text { Mutant } \\
\text { lines }\end{array}$ & $\begin{array}{c}\text { M6. } \\
122.1\end{array}$ & \begin{tabular}{|c|} 
M6. \\
238.1 \\
\end{tabular} & $\begin{array}{c}\text { M6. } \\
238.2\end{array}$ & $\begin{array}{r}\text { M6. } \\
\text { 353.1 } \\
\end{array}$ & $\begin{array}{c}\text { M6. } \\
420.1 \\
\end{array}$ & $\begin{array}{c}\text { M6. } \\
\text { 517.1 } \\
\end{array}$ & $\begin{array}{c}\text { M6. } \\
\text { 517.2 } \\
\end{array}$ & $\begin{array}{c}\text { M6. } \\
801.1\end{array}$ & $\begin{array}{c}\text { M6. } \\
113.3 \\
\end{array}$ & $\begin{array}{c}\text { M6. } \\
200.2 \\
\end{array}$ & $\begin{array}{c}\text { Gelora } \\
\text { (Parent) }\end{array}$ \\
\hline M6.122.1 & 1.000 & & & & & & & & & & \\
\hline M6.238.1 & 0.308 & 1.000 & & & & & & & & & \\
\hline M6.238.2 & 0.346 & 0.346 & 1.000 & & & & & & & & \\
\hline M6.353.1 & 0.327 & 0.288 & 0.250 & 1.000 & & & & & & & \\
\hline M6.420.1 & 0.288 & 0.327 & 0.365 & 0.308 & 1.000 & & & & & & \\
\hline M6.517.1 & 0.308 & 0.231 & 0.269 & 0.327 & 0.365 & 1.000 & & & & & \\
\hline M6.517.2 & 0.346 & 0.346 & 0.308 & 0.327 & 0.327 & 0.269 & 1.000 & & & & \\
\hline M6.801.1 & 0.308 & 0.308 & 0.385 & 0.327 & 0.250 & 0.385 & 0.269 & 1.000 & & & \\
\hline M6.113.3 & 0.346 & 0.269 & 0.350 & 0.327 & 0.212 & 0.308 & 0.269 & 0.269 & 1.000 & & \\
\hline M6.200.2 & 0.350 & 0.269 & 0.423 & 0.365 & 0.365 & 0.346 & 0.308 & 0.269 & 0.269 & 1.000 & \\
\hline Gelora (parent) & 0.308 & 0.269 & 0.385 & 0.327 & 0.288 & 0.385 & 0.269 & 0.269 & 0.269 & 0.385 & 1.000 \\
\hline
\end{tabular}

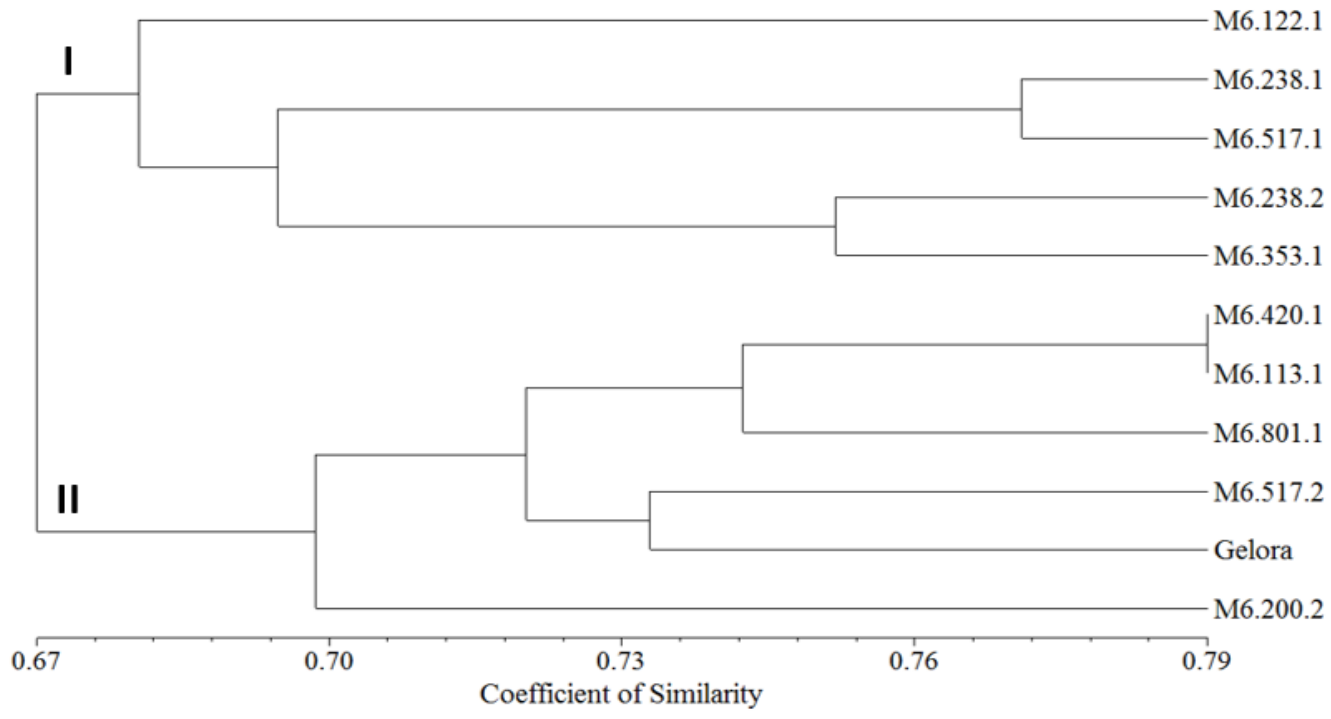

Figure 3. UPGMA dendrogram based on Nei's (1973) genetic distance summarizing the data for differentiation between 10 chili genotypes according to a microsatellite analysis. M6.121.1 to M6.200.1 are the mutant lines, and the control (parent) was Gelora 
The EMS-induced genetic variations in the chili pepper are shown by morphological characteristics that differ from those of their parent. Three mutant lines (i.e., M6.113.3, M6.517.2, and M6.420.1) demonstrated high tolerance to ChiVMV and should be further assayed for their potential. In the present study, morphological and SSR analysis successfully characterized and identified these mutant lines, as reflected by the genetic variation among mutant lines and their parent. Further sequencing to reveal nucleotide variation in these mutants in specific locus would be useful to identify specific allele which might be responsible for controlling ChiVMV tolerant character. The obtained mutants are valuable genetic resources to increase genetic variability and to improve chili pepper varieties resistant to viruses in Indonesia.

\section{ACKNOWLEDGEMENTS}

The authors thank Iswari Dewi for her useful feedback to improve this manuscript and Sherly Anggraini for her technical assistance in conducting the experiments. The authors are also grateful to The Indonesian Agency for Agricultural Research and Development for financial support of this research through ICABIOGRAD budget management (Grant No. 1798.101.001.052).

\section{REFERENCES}

Ajjapplavara PS, Patil SS, Hosmani RM, Patil AA, Gangaprasad S. 2005 Correlation and path coefficient analysis in chili. Karnataka J Agric Sci 18 (3): 748-751.

Albar L, Bangratz-Reyser M, Herbrard E, Ndjiondjop MN, Jones M, Ghesquiere A. 2006. Mutation in the $\operatorname{elF}$ (iso) $4 G$ translation initiation factor confers high resistance of rice to Rice Yellow Mottle Virus. Plant J 47: 417-426. DOI:10.111/j.1365.313x.2006.02792.x.

Alonso JM, Stepanova AN, Leisse TJ, Kim CJ, Chen HP. 2003. Genomewide insertional mutagenesis of Arabidopsis thaliana. Science 301 (5633): 653-657. DOI: 10.1126/science.1086391.

Alvarez A, Fuentes JL, Puldón V, Gómez PJ, Mora L, Duque MC, Gallego G, Tohme JM. 2007. Genetic diversity analysis of Cuban traditional rice (Oryza sativa L.) varieties based on microsatellite markers. Genet Mol Biol 30 (4): 1109-1117. DOI: 10.1590/S141547572007000600014.

Anh TTT, Tran DK, Tran DD, Tran DX. 2018. Identification of phenotypic variation and genetic diversity in rice (Oryza sativa L.) mutants. Agriculture. [Switzerland]. DOI: 10.3390/agriculture8020030.

Anupam A, Imam J, Quatadah SM, Siddaiah A, Das SP, Variar M, Mandal NP. 2017. Genetic diversity analysis of rice germplasm in Tripura state of Northeast India using drought and blast linked markers. Rice Sci 24 (1): 10-20. DOI: 10.1016/j.rsci.2016.07.003.

Arisha MH, Liang BK, Shah SNM, Gong ZH, Li DW. 2015. Kill curve analysis and response of first generation Capsicum annuиm L. B12 cultivar to ethyl methanesulfonate. Genet Mol Res 13 (4): 1004910061. DOI: $10.4238 / 2014$

Aslam K, Arif M. 2014. SSR analysis of chromosomes 3 and 7 of rice (Oryza sativa L.) associated with grain length. Pak J Bot 46 (4): 13631373.

Aswaneeza KA, Rawaidah N, Rodrigues KF, Cheong BE. 2015 Evaluation of the mutagenic effect of ethyl methanesulfonate on hexokinase nuclear DNA locus of Solanum lycopersicum. Proceeding of International Conference on Advances in Science, Technology \& Natural Resources (ICASETNR-15). Kota Kinabalu, Malaysia, 27-28 August 2015. DOI: 10.15242/iicbe.c0815048S.
Bahurupe JV, Sakhare SB, Kulwal PL, Akhare AA, Pawar, BD. 2018. Genetic diversity analysis in chili (Capsicum annuum L.) found in Manipur using RAPD markers. Intl J Curr Microbiol Appl Sci 7 (10): 257-262. DOI: 10.20546/ijcmas.2018.710.027.

Bijalwan P, Mishra AC. 2017. Correlation and path coefficient analysis in bird's eye chili (Capsicum frutescens L.,) for yield and yield attributing traits. Intl J Agric Sci Res 7 (3): 259-266. DOI: 10.24247/ijasrjun201733.

Can ND, Yoshida T. 1999. Genotypic and Phenotypic variances and covariance's in early maturing grain sorghum in a double cropping. Plant Prod Sci 2 (1): 67-70. DOI: 10.1626/pps.2.67.

Chattopadhyay A, Sharani AB, Nuka D, Subrata D. 2011. Diversity of genetic resources and genetic association analyses of green and dry chilies of Eastern India. Chilean J Agric Res 71 (3): 350-356. DOI: 10.4067/S0718-58392011000300002.

Cheng J, Zhao Z, Li B, Qin C, Wu Z, Trejo-Saavedra DL, Luo X, Cui J, Rivera-Bustamante RF, Li S, Hu K. 2016. A comprehensive characterization of simple sequence repeats in pepper genomes provides valuable resources for marker development in Capsicum. Sci Rep 6: 1-12. DOI: 10.1038/srep18919.

Dhaliwal MS, Yadav A, Jindal SK. 2014. Molecular characterization and diversity analysis in chili pepper using simple sequence repeats (SSR) markers. Afr J Biotech 13 (31): 3137-3143. DOI: 10.5897/ajb2014.13695.

Falconer DS. 1989. Introduction to Quantitative Genetics. Ronald Press Co, New York. DOI: 10.2307/2985722.

Gandhi ES, Devi AS, Mullainathan L. 2014. The Effect of ethyl methane sulphonate and diethyl sulphate on chili (Capsicum annuum L.) in $\mathrm{M}_{1}$ generation. Intl Lett Nat Sci 10: 18-23. DOI: 10.18052/www.scipress.com/ilns.10.18.

Geleta LF, Labuschagne MT, Viljoen CD. 2005. Genetic variability in pepper (Capsicum annuиm L.) estimated by morphological data and amplified fragment length polymorphism markers. Biodivers Conserv 14 (10): 2361-2375. DOI: 10.1007/s10531-004-1669-9.

Giarrocco LE, Marassi MA, Salerno GL. 2007. Assessment of the genetic diversity in argentine rice cultivars with SSR Markers. Crop Sci 47 (2): 853-860. DOI: 10.2135/cropsci2005.07.0198.

Greene EA. 2003. Spectrum of chemically induced mutations from a large-scale reverse-genetic screen in Arabidopsis. Genetics 164 (2): 731-740.

Hashimoto M, Neriya Y, Yamaji Y, Namba S. 2016. Recessive resistance to plant viruses: Potential resistance genes beyond translation initiation factors. Front Microbiol 7: 1695-1706. DOI: 10.3389/fmicb.2016.01695.

Herrera TG, Duque DP, Almeida IP, Núñez GT, Pieters AJ, Martinez CP, Tohme JM. 2008. Assessment of genetic diversity in Venezuelan rice cultivars using simple sequence repeats markers. Electronic J Biotech 11 (5): 1-14. DOI: 10.2225/vol11-issue5-fulltext-6.

Hull R. 2009. Mechanical inoculation of plant viruses. Curr Protocols Microbiol 13 (Suppl. 13): 16B.6.1-16B.6.4. DOI: 10.1002/9780471729259.mc16b06s13.

Hidayat SH, Endang O, Manzila I, Sujiprihati S. 2012. Occurrence of Chili Veinal Mottle Virus (ChiVMV) in Indonesia and response of chili germplasms to ChiVMV infection. J Intl Society Southeast Asian Agric Sci 18 (2): 55-61.

Kanyuka K, Druka A, Caldwel DG, Tymon A, McCallum N, Waugh R. 2005. Evidence that the recessive by Movirus resistance locus rym 4 in barley corresponds to the eukaryotic translation initiation factor $4 \mathrm{E}$ gene. Mol Plant Pathol 6: 449-458. DOI: 10.1111/j.13643703.2005.002.x.

Kenyon, Kenyon L, Kumar S, Tsai WS, Hughes JD. 2014. Virus diseases of peppers (Capsicum spp.) and their control. Adv Virus Res 90 (4): 297-354. DOI: 10.1016/B978-0-12-801246-8.00006-8.

Khalil F, Xiao N, Tayyab M, Cheng P. 2018. Screening of EMS-induced drought-tolerant sugarcane mutants employing physiological, molecular and enzymatic approaches. Agronomy 8 (226): 1-13. DOI: 10.3390/agronomy8100226.

Kwon YS, Kim KM, Kim DH, Eun MY, Sohn JK. 2002. Marker-assisted introgression of quantitative trait loci associated with plant regeneration ability in anther culture of rice (Oryza sativa L.). Mol Cells 14 (1): 24-28.

Liu K, Muse SV. 2005. PowerMaker: An integrated analysis environment for genetic marker analysis. Bioinformatics 21 (9): 2128-2129. DOI: 10.1093/bioinformatics/bti282. 
Manzila I, Gunaeni N, Kusandriani Y, Priyatno TP. 2015. Resistance and phenotypic character of chili M2 mutant lines against Chili Veinal Mottle Virus. J Agrobiogen 11 (2): 73-80.

Mariyono J, Bhattarai M. 2016. The economic aspects of chili production in Central Java. Econ J Emerg Markets 8 (2): 85-97. DOI: 10.20885/ejem.vol8.iss2.art1.

Jodi MY, Madalageri MB, Ganiger VM, Bhuvaneswari G, Patil HB, Kotikal YK. 2017. Character association and path analysis studies for yield and yield attribute in green chili (Capsicum annuиm L.) Vegetos 30 (2): 369-373. DOI: 10.5958/2229-4473.2017.00100.8

Nachimuthu VV, Muthurajan R, Duraialaguraja S, Sivakami R, Pandian BA, Ponniah G, Gunasekaran K, Swaminathan MKSK, Sabariappan R. 2015. Analysis of population structure and genetic diversity in rice germplasm using SSR markers: An Initiative towards association mapping of agronomic traits in Oryza Sativa. Rice 8 (1): 62-67. DOI: 10.1186/s12284-015-0062-5.

Narayana SS, Singh P. 2015. Statistical and Biometrical Techniques in Plant Breeding 5th ed. Kalyani Publishers, New Delhi.

Nei M. 1973. Analysis of gene diversity in subdivided populations. Proceedings of the National Academy of Sciences of the United States of America. 70 (12): 3321-3323.

Nieto C, Morales M, Orjeda G, Clepet C, Monfort A, Sturbois B, Puigdomènech P, Pitrat M, Caboche M, Dogimont C. 2006. An eIF4E allele confers resistance to an uncapped and non-polyadenylated RNA virus in melon. Plant J 48: 452-462. https://doi.org/10.1111/j.1365313X.2006.02885.x.

Olasupo FO, Ilori1 CO, Stanley EA, Owoeye TE, Igwe DO. 2018. Genetic analysis of selected mutants of cowpea (Vigna unguiculata [L.] Walp) using simple sequence repeat markers. Am J Plant Sci 9 (13): 27282756. DOI: 10.4236/ajps.2018.913199.

Qosim WA, Rachmadi M, Hamdani JS, Nuri I. 2013. Phenotypic performance, variability, and heritability of 32 high yielding red pepper genotypes. Journal Agronomi Indonesia 41 (2): 140-146.

Ramezani P, Siavozh M, More AD, Ebrahimi M, Dastan S. 2017. Gamma rays and EMS induced flower color mutation in grass pea (Lathyrus sativus Linn.). Tarim Bilimleri Dergisi 23 (4): 423-427. DOI 10.15832/tbd. 13090

Rohlf FJ. 2017. NTSYSpc Numerical Taxonomy and Multivariance Analysis System, Version 2.02. Setauket, New York.

Sadat S, Hoveize M. 2012. Mutation induction using ethyl methanesulfonate (EMS) in regenerated plantlets of two varieties of sugarcane CP48-103 and CP57-614. Afr J Agric Res 7 (8): 12821288. DOI: $10.5897 / A J A R 11.1345$.

Salem KFM, Sallam A. 2016. Analysis of population structure and genetic diversity of Egyptian and exotic rice (Oryza sativa L.) genotypes. Comptes Rendus Biologies 339 (1): 1-9. DOI: 10.1016/j.crvi.2015.11.003
Schulman AH. 2007. Molecular markers to assess genetic diversity. Euphytica 158 (3): 313-321. DOI: 10.1007/s10681-006-9282-5.

Shalaby TA, El-Banna A. 2013. Molecular and horticultural characteristics of in vitro induced tomato mutants. J Agric Sci 5 (10): 155-163. DOI: 10.5539/jas.v5n10p155.

Sharmin A, Ekramu H, Masudul H, Fahima K. 2018. Molecular diversity analysis of some chili (Capsicum spp.) genotypes using SSR markers. Am J Plant Sci 9 (3): 368-379. DOI: 10.4236/ajps.2018.93029.

Shah H, Khalid S, Ahmad I, 2001. Prevalence and distribution of four pepper viruses in Sindh, Punjab and North-West Frontier Province. Online J Biol Sci 1: 214-217.

Smith JSC, Chin ECL, Shu H, Smith OS, Wall SJ, Senior ML, Mitchell SE, Kresovich S, Ziegle J. 1997. An evaluation of the utility of SSR loci as molecular markers in maize (Zea mays L.): Comparisons with data from RFLPs and Pedigree. Theor Appl Genet 95 (1-2): 163-173. DOI: $10.1007 / \mathrm{s} 001220050544$.

Sreelathakumary I, Rajamony L. 2004. Variability, heritability and genetic advance in chili (Capsicum annuum L.). J Trop Agric 42 (1-2): 3537

Till BJ, Cooper J, Ti TH, Colowit P, Greene EA. 2007. Discovery of chemically induced mutations in rice by tilling. BMC Plant Biol. 7:112. DOI: 10.1186/1471-2229-7-19.

Tsai, H, Howell T, Nitcher R, Missirian V, Watson B, Ngo KJ, Lieberman M, Fass J, Uauy C, Tran RK, Khan AA, Filkov V, Tai TH, Dubcovsky J, Comai L. 2011. Discovery of rare mutations in populations: Tilling by sequencing. Plant Physiol 156 (3): 1257-1268. DOI: $10.1104 / p p .110 .169748$

Uchida N, Sakamoto T, Kurata T, Tasaka M. 2011. Identification of EMSinduced causal mutations in a non-reference Arabidopsis thaliana accession by whole genome sequencing. Plant Cell Physiol. 52 (4): 716-722. DOI: $10.1093 / \mathrm{pcp} / \mathrm{pcr} 029$.

Yadeta B, Belew D, Gebreselassie W, Marame F. 2011. Variability, heritability and genetic advance in hot pepper (Capsicum annuum L.) genotypes in West Shoa Ethiopia. American-Eurasian J Agric Envir Sci 10: 587-592.

Yoshii M, Yoshioka N, Ishikawa M, Naito S. 1998. Isolation of an Arabidopsis thaliana mutant in which the multiplication of both Cucumber Mosaic Virus and Turnip Crinkle Virus is affected. J Virol 72: 8731-8737.

Yoshii M, Nishikori M, Tomita K, Yoshioka N, Kozuka R, Naito S, Ishikawa M. 2004. The Arabidopsis cucumovirus multiplication 1 and 2 loci encode translation initiation factors $4 \mathrm{E}$ and $4 \mathrm{G}$. J Virol 78 : 6102-6111. DOI: 10.1128/JVI.78.12.6102-6111.2004

Zalapa J, Cuevas H, Zhu H, Steffan S, Senalik D. 2012. Using nextgeneration sequencing approaches to isolate simple sequence repeat (SSR) loci in the plant sciences. Am J Bot 99: 193-208. DOI: 10.3732/ajb.1100394. 